This is an electronic reprint of the original article. This reprint may differ from the original in pagination and typographic detail.

Author(s): Pecoraro, Maria; Uusitalo, Outi

Title: $\quad$ Conflicting values of ethical consumption in diverse worlds - A cultural Approach

Year: $\quad 2014$

Version:

Please cite the original version:

Pecoraro, M., \& Uusitalo, O. (2014). Conflicting values of ethical consumption in diverse worlds - A cultural Approach. Journal of Consumer Culture, 2014(14 (1)), 4565. https://doi.org/10.1177/1469540513485273

All material supplied via JYX is protected by copyright and other intellectual property rights, and duplication or sale of all or part of any of the repository collections is not permitted, except that material may be duplicated by you for your research use or educational purposes in electronic or print form. You must obtain permission for any other use. Electronic or print copies may not be offered, whether for sale or otherwise to anyone who is not an authorised user. 


\title{
Conflicting Values of Ethical Consumption in Diverse Worlds - a Cultural
}

\section{Approach}

\begin{abstract}
This paper examines the plurality of ethical consumption and aims to illustrate how consumers cope with its complexity in the context of everyday food consumption. This study seeks to outline the tensions that consumers inevitably face when pursuing ethical choices and to shed light on the various ways in which they solve these tensions in the rhythms of everyday life. The research applies Boltanski and Thévenot's theory of orders of worth as an interpretive framework. The research data has been collected from Finnish online discussion forums in which consumers debate various aspects of ethical food consumption. The analysis indicates that the participants in the discussions recognize various understandings of ethical consumption which may be accompanied by insecurities about the "right" ones. However, the research suggests that consumers are able to solve fundamental tensions in ethical food consumption by carrying out different types of practices.
\end{abstract}

Keywords

Ethical food consumption; tension; value; everyday life

\section{Introduction}

As the body of knowledge on ethical consumption has expanded, its tendency towards multiple interpretations has become obvious. Ethical consumption is a complex and challenging phenomenon to academic research and theoreticians as well as to consumers attempting to pursue it. (Cherrier, 2005; Moisander, 2007; Szmigin and Carrigan, 2005). It could be considered a peculiar phenomenon in Western consumer cultures, one that invites and challenges consumers to consider their everyday consumption practices from a moral perspective. This study focuses on exploring the plurality of ethical consumption and increasing understanding how consumers cope with its complexity in the context of everyday food consumption. 
Previous research has regarded the conflicts inherent in ethical consumption mainly from the perspective of the individual consumer. While a large body of research on ethical consumption has addressed the ethical complexities and conflicts as dilemmas for individuals in terms of values, motivation and decision making (e.g. Shaw and Shiu, 2003; Shaw et al., 2000), more studies are needed to increase understanding of ethical consumerism as a cultural process within a society (Barnett, 2005a; Dolan, 2002; Moisander 2007). This paper contributes to the theoretical discussion on the complexity of ethical consumption by considering it as a cultural process. In this line of thinking, ethical consumption is here understood as a complex, culturally constructed phenomenon which forms and develops in the interplay of social and cultural symbol and value systems with consumers' everyday practices. Thus, the notion of culture refers to the systems of representation through which people make sense of their everyday life including both cultural discourses and everyday discursive, social and material practices. Culture is viewed to be produced, transformed and contested in social interaction. (Geertz, 1973; Hall, 1997.)

In this research the concept of ethical consumption is understood in its broadest sense, as referring to discourses and practices of consumption in which the consumer somehow takes into account the possible corollary or indirect effects of his or her choices, whether this means an informed conscious consumption choice or a refusal to consume (Harrison, Newholm and Shaw, 2005). The general purpose of this study is to deepen our understanding of the complexity of ethical food consumption by illuminating how consumers participating in a number of Finnish online discussion forums cope with the various contradictions and discrepancies which they encounter when discussing and living up to ethical consumption. Given the proclivity of food products and food consumption to raise both individual and cultural conflicts and tensions (Halkier, 2001; Thompson and Troester, 2002; Tulloch and Lupton, 2002; Warde, 1997) we anticipate that the context of food will be fertile ground for study. More precisely, the study investigates the dynamics 
between different discourses of ethical food consumption by exploring how they are linked together, and what kinds of tensions they induce. Secondly, this research contemplates various cultural practices which consumers use to cope with the plurality and complexity of ethical food consumption in their ordinary everyday life.

\section{The complexity of ethical consumption}

The ambiguity of ethical consumption is manifested in a wide range of overlapping and intersecting concepts offering a variety of names for the phenomenon, making reference often to ethical, green and anti-consumerism. Concepts such as sustainable consumption (Dolan, 2002), critical consumption (Littler, 2005; Sassatelli, 2006), political consumption (Micheletti, 2003), green consumption (Moisander, 2007), socially responsible consumption (Anderson and Cunningham 1972), conscious consumption (Szmigin, Carrigan and McEachern, 2008) or social consumption (Devinney, Auger and Eckhardt, 2010) refer to more or less the same phenomenon, each one emphasizing different aspects of it.

An individual consumer is caught in a web of different kinds of responsibilities and obligations in his / her everyday life. The routine purchase of groceries is not always considered from an ethical perspective. The ethical argument might be only one premise of consumption choice among others, which could for instance be health, economy, convenience or timesaving (Caruana, 2007; Devinney, Auger and Eckhardt, 2010: 112; Schor, Slater, Zukin and Zelizer, 2010; Thorgersen, 2005).

The previous literature indicates that the meanings and practices of ethical consumption are contextual and temporal, depending upon the time and place in which one lives (Cherrier, 2005: 125; Connolly and Prothero, 2008; Halkier, 2001; Newholm, 2005: 123-124). Implicit to the contextual aspect of ethical consumption, the multiplicity of ethical concerns, the fragmentation of practices and the often contradictory information, is the claim that it is impossible to define ethical consumption in any single, consistent way (Attalla and Carrigan, 2001; Devinney, Auger and 
Eckhardt, 2010: 134-136; Micheletti, 2003; Prothero, McDonagh and Dobscha, 2010; Sassatelli, 2006). The research on ethical consumption suggests that issues arising from ethical consumption cause conflicts and tensions for consumers (Barnett, Cloke, Clarke and Malpass, 2005a; OzcaglarToulouse, 2007; Moisander, 2007). Given the complex and ambiguous nature of the phenomenon, the goal of this research avenue is to understand how consumers cope with this ambiguity.

\section{Setting}

The empirical data consists of 12 online discussions (206 pages) collected from eight Finnish discussion forums which date from July 2007 to January 2009. The guiding principle for selection of the discussion threads was naturally to choose dialogues in which themes connected to ethical and moral aspects of food consumption were negotiated richly and variously. The context of the research, Finland, is a country in Western Europe, nevertheless possessing a number of characteristics peculiar to this small country located in the interface of the west and east. Finland is linguistically distinct yet culturally close to the Nordic countries. During the $20^{\text {th }}$ century Finland experienced a swift transfer from an agrarian society to a modern wage earner and consumer society. Finland is regarded as the vanguard of European countries in terms of education, social mobility, and decrease in the income- and gender differences. (Lehtonen, 2008: 279). The support from the welfare state together with the relatively late but quick shift to the consumer society comprise the roots of the contemporary Finnish society.

The approach to the data is text-based, focusing on analyzing the construction of cultural and social meaning-making through online dialogues (Stillar, 1998: 107). The research data is in a naturally occurring state, which means that the researcher has not influenced the generation of the data (McKee and Porter, 2009: 82-83; Moisander and Valtonen, 2006: 69-70). Due to anonymity and the faceless nature of online discussions, the social desirability bias, which is common in the context of studying ethical consumption, might be diminished. (Devinney, Auger and Eckhardt, 2010: 56-57) 
We embarked upon the detailed analysis by scanning through the data and identifying major themes that emerged from the online discussions. The participants in these online discussions of ethical consumption appeared to balance between various levels of interpretations; they constructed their interpretation of ethical consumption either on their everyday experiences, personal feelings and beliefs, or on public knowledge produced by so-called experts. After the first round of analysis we sorted the whole corpus of data by coding the different values that emerged in the discussions with the help of ATLAS.ti software. In the second phase of the analysis we grouped all 46 different values into thematic units or constellations based on careful content analysis of the data. This grouping gave insights into how the values of ethical consumption related to the private sphere differ from those of the public sphere. In the following step, we examined the data through the interpretive theoretical framework of Orders of worth (Boltanski and Thévenot, 2006). (See Table 1). This framework informed the further analysis, which proceeded from outlining the tensions to understanding the dynamics between different interpretations of ethical food consumption. To conclude, in the last phase of analysis we identified different practices by which consumers cope with and solve tensions that emerge from conflicting interpretations of ethical consumption. The basic assumption of the theory is that tensions and disputes are an integral part of social life and that modern societies are not a single social order but an interweaving of multiple orders. Six "worlds", systematic and coherent principles of evaluation, can be identified. (Boltanski and Thévenot, 2006: 40-41, 216). These worlds are not bound to particular social domains such as institutions, individuals, or groups, but they coexist in the same social space side by side (ibid: 151). Each of these worlds (civic, market, inspired, fame, industrial, and domestic) are based on a higher common principle, which is the basis for evaluation. The first is the inspired world, which is founded on ideals such as inspiration, authenticity, and autonomy. The domestic world, in turn, is firmly grounded on the family, kinship and respect for tradition, and personal identity is based on his/her role in these structures. Thirdly, the world of fame is comprised of public opinion, fame and 
spectacular visibility. The fourth is the civic world, which builds on ideals of solidarity, participation, democratic decision making and conformity to shared rules. The fifth is the market world, in which the core elements are competition and competitors and in which worth is evaluated according to money and ownership. Lastly, the industrial world is based on efficiency, performance and a strong belief in irrevocable progression. This is the world of experts who use and dictate tools, methods, plans, statistical information and expert concepts. (ibid: 159-203) Confrontation between these different worlds produces tensions, even clashes. Nevertheless, if the parties are oriented towards the notion of the common good (which belongs to none of the conflicting parties) a fragile "compromise" may evolve which will reconcile the tensions and settle the dispute (ibid : 9).

Table 1 Orders of worth (Boltanski and Thévenot 1999; 2006)

\begin{tabular}{lllllll}
\hline World & Inspired & Domestic & Civic & Fame & Market & Industrial \\
\hline $\begin{array}{l}\text { Mode of } \\
\text { evaluation } \\
\text { (worth) }\end{array}$ & $\begin{array}{l}\text { Creativeness, } \\
\text { nonconformity }\end{array}$ & $\begin{array}{l}\text { Esteem, } \\
\text { reputation }\end{array}$ & $\begin{array}{l}\text { Collective } \\
\text { interest }\end{array}$ & Renown & Price & $\begin{array}{l}\text { Productivity, } \\
\text { efficiency }\end{array}$ \\
\hline $\begin{array}{l}\text { Format of } \\
\text { relevant } \\
\text { information }\end{array}$ & Emotional & $\begin{array}{l}\text { Oral, } \\
\text { exemplary }\end{array}$ & $\begin{array}{l}\text { Formal, } \\
\text { official }\end{array}$ & Semiotic & Monetary & $\begin{array}{l}\text { Measurable: } \\
\text { criteria, } \\
\text { statistics }\end{array}$ \\
\hline $\begin{array}{l}\text { Elementary } \\
\text { relation }\end{array}$ & Passion & Trust & Solidarity & Recognition & Exchange & $\begin{array}{l}\text { Functional } \\
\text { link }\end{array}$ \\
\hline
\end{tabular}

\section{Findings}

The analysis threw light on the circumstances in which consumers balance and compromise between abstract values and the mundane realities and constraints of everyday life. The discussion participants seem to be well aware of the diverse meanings of ethical consumption and to recognize different approaches and perspectives. This openness to various interpretations, plurality and complexity invokes in the participants feelings of ambiguity and uncertainty, leading to selfreflexivity and questioning of personal choices, as the following quotation shows. 
I buy quite a bit all kinds of things from the local eco boutique. And I waste my money on the products made by local artisans (Especially if recycled materials are used). Usually I choose wines made of organically grown grapes and fair trade coffee. At the same time I smoke destructive 'addiction cigarettes' produced by tobacco industry and run after special offers one kind or another. And so I think that my actions are without rhyme or reason. (17 July '07, 21:22)

At one extreme are ideals, values and strict principles, while at the other there are the realities of everyday life: limited resources and restricted means to realize the ideals. In the online discussions the participants identify the irony of ethical consumption: the richer the consumer, the more powerful he or she actually becomes (Dolan, 2002).

The online discussions on ethical food consumption are polyvocal, encouraging resistance, offering serious criticism, but also joking. Resistance to ethical consumption is typically based on the belief that an individual is unable to influence global development trends by his/her consumption choices. The analysis suggests that the discourses of ethical consumption diverge according to whether they are interpreted in the context of private life or explicated through scientific and expert knowledge from a global perspective. However, the diverging interpretations of ethical consumption do not necessarily contradict each other, but rather they overlap and crisscross in various ways in everyday dialogues. We will now discuss the discourses of ethical consumption in value terms in order to relate them to the interpretive framework.

\section{Discourse of living the good life}

In the private sphere, ethical food consumption is constructed as an action by which the consumer aims to live a good and virtuous life and keep his or her conscience clear. As the following quotation demonstrates, ethical consumption is occasionally manifested as a luxury of everyday life and as an attempt at authenticity, spirituality, and the fostering of traditions. 
When you have to purchase something, one should prefer quality and durability. When you save in other living costs, you have opportunity to buy more expensive food and you don't have to buy the cheapest industrially produced food. Accordingly, I call it luxury of everyday life when you can afford buying quality and organic food. (5 Oct ' $08,12: 49$ )

In the private sphere, the concept of ethical consumption is based on consumers' personal experiences, memories, and stories, which anchor abstract meanings to everyday life. Information about the possible consequences of consumption choices seems to empower and commit the consumer to practice ethical consumption, but at the same time it gives him or her guilty conscience, which, in turn, might direct the consumer towards morally sensitive consumption choices. The discourse of living a good life embodies and rests on two main values, reasonableness and simplicity. Reasonableness translates to the use of common sense and the avoidance of excess, and also incorporates the ideas of relativity and flexibility whereby the individual is free to decide how to practice ethical consumption, taking into account his or her personal situation and resources. Ethical consumption as it emerges from the private sphere respects personal freedom and tolerance, so consumers are not allowed to condemn or blame each other or lay down rules. In this sense, ethical consumption might convert into a zero sum game in which the consumer tries to keep his or her conscience clear by compensating unethical consumption choices with ethical ones and practicing trade-offs in everyday life. The second main value in this discourse is simplicity, especially voluntary simplicity (Elgin, 1981; Etzioni, 1998; Shaw and Newholm, 2002). In the context of ethical consumption, simplicity translates into ideals of an overall reduction in consumption and the simplification of the daily diet in order to gain spiritual pleasures and experiences.

The discourse of living a good life that emerges in the private sphere derives from the worlds of inspiration and markets and from the domestic world. The freedom to choose personally what ethical consumption means conforms to the market world's nourishing of the ideal of 
consumer sovereignty. In the world of markets it is entirely natural that a consumer should seek to connect self-interest and the common good through ethical consumption (Boltanski and Thévenot, 2006: 196-203). Also the idea of buying a clear conscience conforms to the logic of the market, in which the worth of things is evaluated only in terms of money. Secondly, high appreciation of traditions and the family connects the discourse to the domestic world (ibid: 164-165). From this perspective, rustic, rural handmade items and local traditional food represent what is valued in the domestic world. Thirdly, the meaning of ethical consumption in this discourse is clearly connected to the inspired world, where worth is based on ideals of authenticity, emotionality and inspiration (ibid: 159-164). In this view, ethical consumption represents individuality, a chance for selfexpression and an experience of authenticity (Barnett et al., 2005b; Cherrier, 2007; Inglehardt, 2006; Kozinets and Handelman, 1998).

\section{Discourse of saving the world}

In the public sphere, in the realm of institutions, work and communities, ethical consumption is founded on the idea of saving the world. In this sense, it stands for the abandonment of personal interests, at times even sacrificing oneself for the common good. The perspective of experts is articulated in concepts such as diminishing the ecological footprint, decreasing the ecological load or improving ecological efficiency. In fact, the expert's perspective aspires to strip away the influence of personal memories and emotions which represent ethical consumption as rational and effective action. The discourse of saving the world is based on two main values, solidarity and comprehensiveness. Solidarity connects with the idea of a global citizen-consumer whose role obliges him or her to act for the common good, to share prosperity also with distant others (Barnett et al., 2005a; Goig, 2007; Micheletti, 2003) In this sense, ethical food consumption stands for making sacrifices for the common good, renouncing autonomy and setting personal interests to one side. Following the guidelines and norms of ethical consumption created and formulated by experts presupposes not only trust in them but also confidence in other consumers' 
goodwill as well. The second important value in the discourse of saving the world is comprehensiveness, which incorporates the idea of a vast interconnectedness between everyday behaviour in the supermarket and the complex global course of events. Especially experts try to tackle the bigger picture, producing cause-effect models to prove how small deeds have global impacts (Giddens, 1991: 64). In the online dialogues comprehensiveness also takes on another meaning: ethical consumption is not merely a matter of consumption but a whole way of life and a philosophy which forms a multiplicity of sub-cultures of ethical consumers.

The discourse of saving the world lies in the civic and industrial worlds. The responsible role of consumer-citizen with an emphasis on global responsibility and solidarity links ethical consumption to the civic world, where worth is based on values such as fairness, equality and collective conformity (Boltanski and Thévenot, 2006: 185). Similarly, the worth of ethical consumption is evaluated in terms of efficiency and productivity, which are the most important values in the industrial world. Especially experts justify their versions of ethical consumption with arguments familiar to the industrial world.

\section{Tensions of ethical consumption}

The analysis makes it clear that ethical food consumption is found with different values in the private and public spheres. In everyday life, the discourses overlap, depending on the situation and the context. At times, different interpretations of ethical food consumption clash, evoking fiery exchanges of words between participants in the online discussions. Tensions emerge when different interpretations of ethical food consumption are juxtaposed with each other but evaluated according to different criteria. The discussions on ethical food consumption incorporate three types of tensions that the participants confront; tension in terms of power, tension related to consumer culture, and tension in terms of responsibility.

\section{Tension over power}


Consumers striving to practice ethical food consumption in their daily life may come up against tension related to the imbalance of power. They try to contribute to solving various global problems but the means open to them are restricted to relatively small good deeds and choices in the supermarket (Barnett et al., 2005a). The online discussion participants seem to be very aware of the fact that since ethical consumption and its supporters and critics have manifold interests, the information provided for instance by corporations might be regarded critically, with suspicion. A critical attitude towards the information that is made available about ethical food choices and doubts about the guidance given may arouse a fear of the possibility of losing sovereignty in consumption choices which, in turn, might even impugn the rationality of ethical consumption. Besides, ethical consumption is a difficult subject to discuss because it easily provokes feelings of guilt and feelings of being made guilty, which threatens ideals of individual freedom.

In the end, buyer has a power to choose what he or she promotes. And if it is wanted to give up freedom of choice, perhaps it would be crucial to pose more arguments than emphasizing personal values. Especially, when on the other side of the scale there are jobs, finance of public services and free enterprise. Finally, I remind that I stand for friendliness to the environment but I am against of eco-communism. (18 July '07, 21:30)

The tension over power in ethical consumption becomes greater when the interpretation emphasizing individual freedom of choice confronts another interpretation which emphasizes the importance of commitment to shared norms and rules. The emphasis on individual freedom in ethical consumption might arise from the ideal of a sovereign consumer belonging to the market world and from the inspired world, through such qualities as authenticity, self-expression and uniqueness. The interpretation demanding commitment and obedience to the common good which emerges from the civic world seems to pose a threat to such things as freedom and inspiration; it directs consumers to accept the slavery of daily routines and imposes new, constricting rules on consumers. Indeed, in the civic world the power of consumers to really influence global problems is understood to be connected to obeying rules and norms and collective discipline. On the other hand, 
the politicized view of consumption induces a fear of fanaticism and politics in self-governing consumers of the market world. The liberal interpretation of ethical food consumption, which emphasizes individual freedom, is defended by the domestic world because the most important criteria for evaluation of ethical consumption here are traditions and respect for the family. The interpretation of ethical consumption that emphasizes efficiency and technical progress, for its part, is connected to the industrial world, which, in turn, criticizes the individualistic interpretation of ethical food consumption not only for its lack of rationality but also for being nostalgic about the past and traditions. In the industrial world the justification and the worth of ethical consumption are based on measurements, concepts launched by experts and their rational application.

\section{Tension of responsibility}

The idea of responsibility is closely linked to the discussion of power. Thus, online discussion turns continually to the question of who is ultimately responsible for the consequences of consumption. The problem of distributing responsibility to individuals is complex since no one can predict the consequences of consumption in the foreseeable future. The view emphasizing consumers' freedom of choice would make consumers responsible only for their personal choices. This concept of individual responsibility arises not only from the market world but also from the worlds of inspiration and the domestic world, which underline the importance of voluntarity, and contextuality, and thus, the meaning of a good intention when evaluating how ethical consumption choices are. In comparison to the concept of ethical consumption that emerges from the civic world, offering consumers guidance, information and education on topical issues might be interpreted as an annoying attempt to make people feel guilty and to impose experts' opinions. Indeed, the feeling of guilt undermines and destroys the pleasures of inspiration and self-expression that are related to ethical consumption.

Everybody makes their personal choices and imposing on some vantage point is always (thumbs down icon that is bad, undesirable). Thus, coercion doesn't do any good but agony. I 
don't want to impose on my ideas of ethical consumption to anyone, because my conscience is not fully clear either. I truly believe that most people try their best. However, the information is needed in order to make right decisions. (26 June '08, 16:04)

The role of information or knowledge is crucial in ethical consumption because it is understood to empower consumers to make conscious and deliberate consumption choices (Attalla and Carrigan, 2001; Berry and McEachern, 2005). Information sensitizes consumers to issues related to ethical consumption, which implies the responsibility to act as well. The idea that responsibility for the consequences of consumption choices falls on consumers themselves does not appeal to all participants in the online discussions. On the contrary, according to some comments, some participants would even like to pass responsibility on to the experts, or to those in the primary stages of the production chain.

As opposed to the individual viewpoint of ethical consumption, the interpretation that emerges in the civic world stresses the duties of the global citizen and his / her social responsibility to reduce inequality and enhance global solidarity (Micheletti, 2003; Clarke, Barnett, Cloke and Malpass, 2007). The understanding arising from the market world, on the other hand, asserts that responsibility can be measured in terms of money, which in practice means that responsibility is simply a matter of making business with. This line of thinking alleges that the consumer bears global responsibility through his or her wallet. However, this line of thinking is strongly criticized from the civic world, of course, and from the individualistic world of inspiration and the domestic world. The statement that responsibility is not something to be measured and calculated in terms of money unites individualistic and collective interpretations of ethical consumption. The interpretation of ethical consumption in the world of inspiration and in the domestic and civic worlds underlines idealistically that ethical consumption choices, like the whole world in general, should be evaluated and measured in terms of human well-being and humanity, not in terms of money. 


\section{Tension related to consumer culture}

This tension embodies the perspectives of social criticism and the politics of everyday life in ethical food consumption. One pole of the tension incorporates social critique related to consumption choices, criticism which could be directed towards the whole western consumer culture with its materialism and wastefulness and its hectic lifestyle. In the online discussions ethical consumption appears as a way of protesting against the problems of global commerce and as an alternative to the mindset based on continuous economic growth. This critical interpretation of ethical consumption arises from the civic world condemning individualism, greed, the pervasive competitiveness and the cult of money.

I think that it wouldn't be necessary that the wheel of economy rolls like it now whirls. If only people just consumed less and bought only useful things. Only jobs would change names...there would be more cobblers, tailors and farmers and less frivolous technology freaks and trifling retailers. (5 Aug '08, 9:36)

The social critique of ethical consumption also displays a tendency to reduce, and sometimes avoid, consumption. In the context of groceries, the simplification and reduction of consumption levels means preferring ingredients produced in the home country and avoiding industrially refined foreign foodstuffs. The criticism of market forces links with the domestic world and the world of inspiration and it is crystallized in the statement that a clear conscience cannot be bought but can be gained only by good intentions and good acts. The most radical voices in the online discussions seriously doubt that one can solve any problems by consumption choices, and call for the abandonment of the consumption-centred way of life, the prevailing logic of economic growth.

On the other hand, a reduction in consumption and a possible deceleration of economic growth trouble the participants in online discussions from the point of view of social welfare and affluence. The online discussions illustrate how people have truly internalized their role as 
consumers and the associated duty to consume to keep economic growth on track. Indeed, the major contradiction of ethical consumption stems from the fact that consuming itself becomes the most important way of expressing discontent with consumer culture.

At the other pole of the tensions inherent in consumer culture the interpretation of ethical consumption is fairly liberal in that ethical consumer choice appears to be one option among others (Shankar et al., 2006). The meaning of ethical consumption is constructed in the context of the prevailing economic order: consumption as such is not questioned or resisted, and so the objective is not extensive political or social change but rather setting the scene for improvements through minor consumption choices. This interpretation is linked to the market world through the idea that a clear conscience can be bought in the form of eco-friendly or fair trade products. Consequently, a liberal interpretation of ethical food consumption evolves into luxury in everyday life.

\section{Tackling tensions in everyday life}

The tensions and sometimes even outright disputes between the different interpretations of ethical consumption are rooted in values. According to Alasdair Macintyre (2007: 48), it is virtually impossible to close value-based debates with rational statements because everything comes down to the fact that the bases of interpretation are founded on different values. In everyday life moral reasoning turns towards intentional actions and deeds, which is a practical way to express and realize ethical beliefs and conceptions (Warde, 2005).

However, the only thing that matters after all is practical deeds, choices, and solutions which contribute attaining something. Beautiful thoughts don't benefit until they are practiced somehow ; ) Choosing the animal- and environmentally friendly products is not difficult, expensive, or else unreasonable demanding. (5 Oct '07, 19:51)

The objective of ethical food consumption is basically twofold: on the one hand to live a harmonious and good life, and on the other to save the world. These objectives could be connected with each other to identify "a common good", a shared value or an objective that would serve as a 
bridge to identify a situational and contextual compromise between different goals that pull in opposite directions. The analysis of online discussions suggests that the different interpretations of ethical consumption could be connected through two major values: firstly, altruism, the selfless concern for the welfare of others and, secondly, respect for human and animal rights and for the environment and nature in general. These "common goods" bridge different interpretations of ethical consumption, constructing situational and contextual compromises between contradicting discourses of ethical consumption. Online discussions reveal five different types of practices of ethical consumption through which consumers are able to reconcile different demands, values and goals related to ethical food consumption. Yet, these "agreements" tend to be situational and fragile by nature. The fundamental tensions related to ethical consumption return before long and new agreements have to be negotiated. Figure 1 displays how ethical food consumption is constructed of different kinds of discourses and values, the tensions between them, the aspirations for the common good and the practices of everyday life through which consumers' not only solve the tensions but also carry out ethical consumerism in their everyday life contexts. In what follows we will discuss the practices of ethical food consumption in detail in order to indicate how these practices resolve tensions and contradiction related to ethical consumption in consumers' everyday life.

Figure 1. The construction of ethical food consumption from the consumer's perspective 


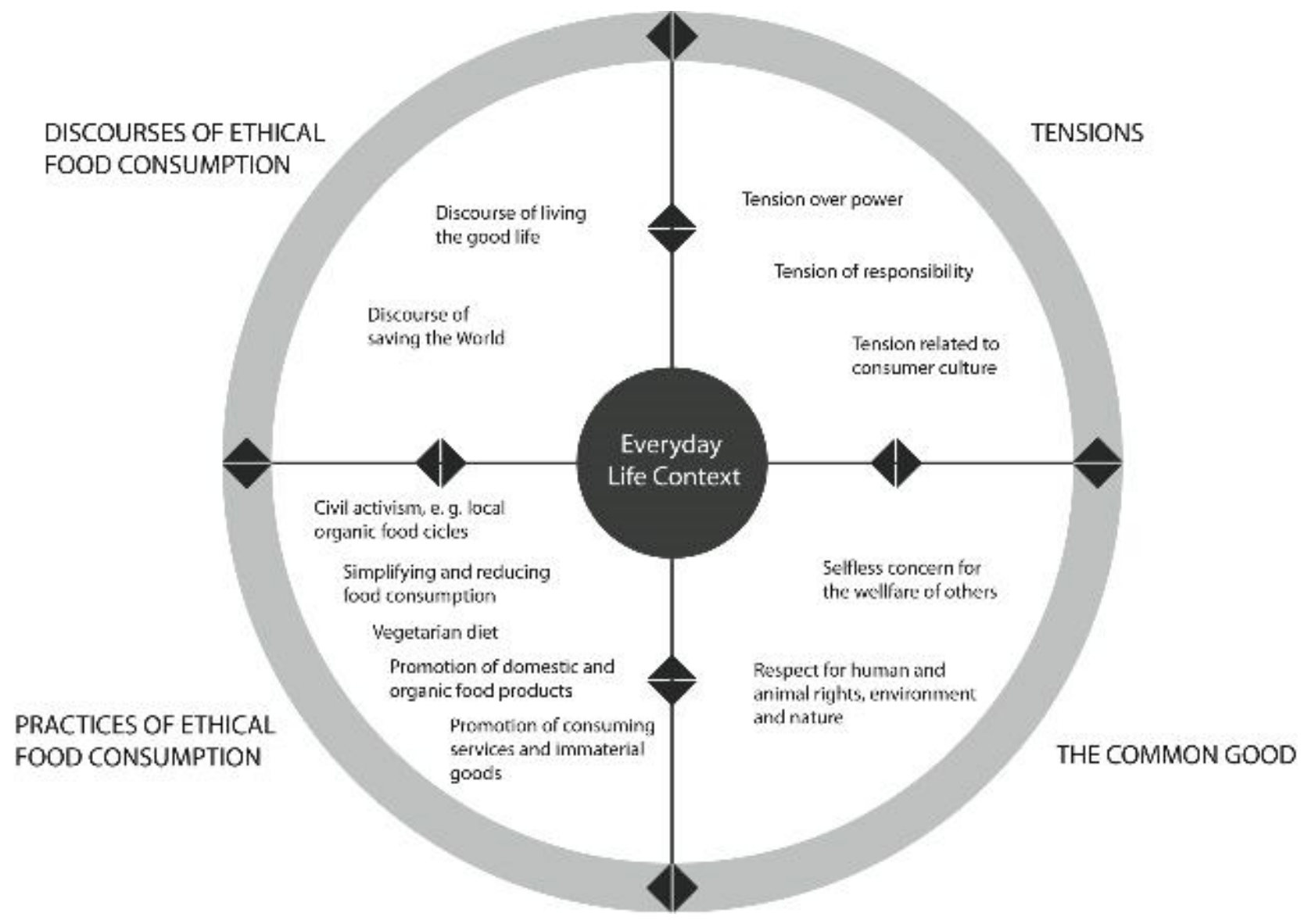

\section{Civil activism}

We have already been a while a member of the university's organic food circle. [...] So if you are interested in organic food it would be worthwhile to find out if there is some sort of organic food circle in the neighbourhood. Usually they have a larger selection of products than in grocery shops and the prices are usually reasonable. (2 Oct. '07, 14:10)

Engagement in civil activism is the first practice of ethical food consumption through which the discussion participants seek to reconcile all three tensions. In practice, civil activism in the context of ethical consumption means self-organized organic food circles that seek alternative patterns of food distribution, connecting local producers with nearby conscientious consumers in order to resolve defects in current food distribution and the inadequate availability of organic food. Civil activism in the context of ethical food consumption is 'grassroots action' to improve perceived defects by organizing alternatives to current institutions and practices. In civil activism the 
perceived need to change is expressed through action, and the direction of influence is from the bottom to the top (Beck, 1992; 1995).

An organic food circle can offer inspiration, spiritual values, and points of reference to values associated with safety, traditions and home. Contributing to alternative food circles can also, for example, appear as a discursive use of power, with the aim of bringing about change in current practices not only by setting an example for other consumers but also by creating coordinated pressure on retailers to provide a selection of organic food products.

\section{Simplifying and reducing food consumption}

Unnecessary goods shouldn't be bought. Neither travelling is desirable. One should eat less (A bit of root veggies, cabbage and a couple of slices of rye bread in a day is enough for an adult). In addition, one should not live in a too big house [...] Life doesn't have to be grey one can take care of intimates, chat with people, spend time doing something, run, walk in the woods. (2 Nov '08, 15:07)

The second way of reconciling the tensions in ethical food consumption is to simplify and reduce the level of consumption. In the online discussions comprehensive simplification is manifested as a social critique against a consumer-centred culture and a busy life style. The focus of simplifying life is on the individual and his or her wellbeing rather than on society as a whole, although it includes criticism of the busy, competitive lifestyle driven by economic values and constantly striving for economic growth. In the context of food consumption, simplification means returning to pure, domestic, traditional ingredients and avoiding of highly refined food products. The idea of simplification of consumption also embodies the ideal of expressing oneself through other means than consumption choices. In addition, restraining oneself from the temptation to consume means empowerment, bearing responsibility and emancipation from the control of business life. At its most extreme, simplification could even mean abandoning the consumer society and returning to an agrarian way of life. 
Yes, it is extremely important that vegetable food has a good taste, and it is good for the body and health. But equally important to me is that the food I eat is ethically and ecologically good and that other living creatures have not suffered or killed for my meal. [...] Altogether, vegetarian diet is an ethical issue for me and eating is a political act, as the consuming in general. (18 Oct, 07, 6:54)

The third practice used to reconcile the tensions related to ethical food consumption is having some kind of vegetarian diet. According to online discussions, a vegetarian diet seems to be the most common way to meet the demands of ethical consumerism in everyday life. In many comments, a vegetarian diet is interpreted as a socially responsible and ecological choice from the standpoint of global food sufficiency. A vegetarian diet fits in with various kinds of ethical ideas about animal rights and the environment. In following a vegetarian diet a consumer is able to connect individual benefit with community benefit in a straightforward way. There are a number of different vegetarian diets, which means that one can tailor the diet according to one's personal needs and self-expression: a vegetarian diet serves as a resource through which one can construct one's identity, and as a means of self-expression. Nevertheless, a vegetarian diet leads to new contradictions related to individual autonomy in some other circumstances. A vegetarian diet is a good, practical compromise which balances the tensions of ethical consumption as long as the sovereignty of the individual is not threatened.

\section{Promotion of domestic and organic food products}

I promote the domestic, organic and locally produced food even though it is more expensive than normal food products. I also favour Fair trade-fruits. Indeed, the quality is so much better than mass produced fruits and veggies. (30 June, '08, 23:17)

The fourth practice used to adjust the tensions related to ethical consumption is promotion of one's own country's food products and especially of organic and Fair trade products. Buying 
Finnish food products, especially those produced locally creates in consumers the feeling that they can affect and perhaps control practices or conditions in agricultural production and the ways in which production animals are treated, even if they have never visited a farm. Promoting the food products of one's home country could be seen as an ecological choice because of shorter transport distances than for foreign food products. The discussion participants especially seem to think that so-called local food is an ethical choice. In addition, they seem to believe that food produced in their own country is not only more ethical but also of better quality, is purer and thus healthier. Apart from the global ecological angle, promoting food produced in one's own country is also selfinterested. Indeed, the participants in online discussions believe that by buying food produced in their own country they are supporting employment nationally and thus the welfare of their country. It is especially in their discussion of this sort of food that consumers show how deeply they believe that it is their responsibility to continue consuming for the sake of their home country, in order to sustain and ensure economic growth. Altogether, promoting Finnish food is interpreted as a responsible choice for fuelling the national economy, ensuring employment and sustaining affluence.

\section{Promotion of consuming services and immaterial goods}

Luckily consuming does not have to mean buying unnecessary stuff. The best consumption is paying for a service: to visit a restaurant or a masseur, to go to the movies, or to take a broken mixer in to repair instead of buying a new one. This way we ensure that we employ in Finland and not in some other country which happens if we buy products "made in ???". (28 Oct, '08, $18: 32)$

The fifth way to solve the tensions related to ethical consumption is to promote the consumption of services of one kind or another. In the context of food consumption this refers, for example, to eating out in restaurants. Consuming services and experiences may give people the opportunity to fulfil themselves as consumers without the guilt that might accompany consuming 
material goods: the immateriality of services frees consumers from the guilt which ruins the joy of consumption. As with consuming nationally produced food products, consuming services also appears to be an ethical choice from the point of view of sustaining domestic employment and prosperity. In spite of the global orientation of ethical consumption in general, the online discussions on ethical consumption do not contain criticism of the fact that how ethical food choices are considered to be determined by self-interested motives such as national wellbeing and economy.

\section{Discussion}

While ethical consumption has become an important phenomenon in the Western economy, it is a complex phenomenon that gives rise to tensions and conflicts. These tensions are visible in the online forum discussions, in which participants deal with the various meanings of ethical food consumption. They seem to focus on the discourses of living a good life and saving the world. This finding confirms the observation made in green commodity discourses that consumers prefer green consumption choices either for macro reasons or for individualized micro reasons that do not necessarily relate to sustainability (Prothero, McDonagh and Dobscha, 2010). This research sheds light on the dynamism of the discussions of ethical food consumption, in which personal everyday experiences and beliefs are mixed up with scientific knowledge and information produced by experts. On the micro level, ethical consumption is manifested in small deeds in everyday life, while expert knowledge aspires to quantify and theorize the issue to offer a holistic macro-level perspective.

Consideration of the data through the interpretive theory of Orders of worth revealed that different interpretations of ethical food consumption arose from different value orientations associated with various worlds (Boltanski and Thévenot, 2006). In the online discussions the various interpretations are intertwined with each other, depending on contextual and situational factors. At times different views of ethical food consumption may conflict with each other and lead to the consumers' encountering tensions when they deliberate on their consumption choices from 
the moral standpoint. The analysis reveals that the participants confront three types of tension: tensions related to consumer culture, tensions related to power and tensions related to responsibility. Previous research has identified several conflicting features of ethical consumption. Dolan (2002: 171) pointed out that the irony of ethical consumption is that the wealthier the consumer, the more powerful he or she becomes.

Our research suggests that consumers confront this "irony" when they use ethical consumption as a resource to resist and criticize the consumption-centred, materialistic, throwaway culture and busy lifestyle. Unexpectedly, the online discussions included only a few radical comments calling for abandonment of this consumption-centred way of life. This might mean that understanding of ethical food consumption is constructed in the context of the prevailing economic order, which revolves around the market world, through the idea that a clear conscience can be bought just like everything else. Also Barnett et al. (2005a: 41) have claimed that ethical consumption supports social distinctions: the display of ethical credentials flaunts people's uneven capacities for practicing ethical consumption. Besides, consumer activism through buying or boycotting strengthens the significance of consumer practices (Connolly and Prothero, 2003; Dolan, 2002).

Sassatelli (2006: 225) has justly remarked that the markets with their many different institutions, interests and powers offer and indeed promote their own versions of what is an "ethical" commodity. This diverts the attention on power, which incorporates the second tensions identified in our research - the tensions over power. These tensions set against each other one interpretation which emphasizes individual freedom of choice and another interpretation which stresses the importance of commitment to collective rules. The issue of how to reconcile autonomy and responsibility, individual agency and collective obligations, is considered to be inherent to discussions about consumption (Barnett et al., 2005: 26). The third tension in ethical food consumption identified in our study is the tension of responsibility, which could be seen as the 
reverse side of the question of power. The online discussions continuously dwelt upon the question of who is ultimately responsible for the consequences of consumption. Several studies suggest that the current tendency to individualize responsibility and globalize the consumer has become a pervasive element of consumer culture, serving the purpose of mobilizing and governing people (Barnett et al., 2005a; Clarke, et al., 2006; Shamir, 2010; Shankar et al., 2006). Moisander (2007), on the other hand, has criticized the tendency to place responsibility for global problems on individuals, claiming it is too heavy a responsibility to bear. Our analysis indicates that the participants understand that responsibility and opportunities to make a difference do not necessarily meet with global goals. It is in this way ethical consumers might confront the tension of responsibility.

In a study conducted by Connolly and Prothero (2008: 141) the participants felt an obligation to act to address global environmental issues but at the same time they felt uneasiness about how to act. The analysis revealed five different practices through which the participants are able to reconcile different demands, values and goals related to ethical food consumption. Thus, consumers may use a number of practices in order to navigate in the complexity of ethical consumption in their everyday life. However, these practices, so called "agreements", tend to be situational and fragile by nature (Boltanski and Thévenot, 2006: 278-281). The elementary tensions related to ethical consumption are always present even though temporary agreements can be found. This study therefore helps us to understand how consumers cope with the complexity of ethical consumption choices in everyday life and underlines the dynamic nature of the phenomenon. Adopting a cultural approach and emphasizing the interdependence of social and individual processes in the co-construction of meanings has allowed us to illustrate and make visible the dynamism in the practices through which consumers make sense of, negotiate and tackle the complex ethical issues in their ordinary life. This perspective emphasizes that consumption 
practices should be understood as processes that tie individuals to larger systems of provision, linking private and public worlds (Trentmann, 2007: 155).

This study examined the complex phenomenon of ethical consumption in the Finnish context. Including only one context might make it more difficult to generalise the results to other cultural contexts. We propose that the results are generalizable at least to the Nordic countries, where the welfare society has kept consumers informed about ethical consumption through consumer education policies (Leire and Tidell, 2005: 1064). It is important to note that the tensions behind ethical consumption are likely to vary according to the cultural context. In the non-Western societies ethical consumption tensions appear to be quite different. For example, two distinct cases from Egypt (Abu-Lughod, 1997; Peterson, 2010) illustrated how the social relations involved in the production and consumption of food seemed to play far more important role in evaluating the ethicalness of a consumption choice than in our study in the Western context. Online discussion forums as data sources also entail limitations to the possibility of evaluating the prevalence of ethical consumption. Indeed, just starting an online discussion on ethical consumption calls for special interest and effort as well as participation in the discussions, so the participants are probably more involved with ethical consumption than most people.

Since ethical consumption is a subject of increasing interest to consumers, producers, the authorities and experts, it is obvious that various interpretations of ethical consumption exist and are permeated by different values, power relations and beliefs. In the present era of heightened awareness of ethical consumption and "responsible business", it is vital to have and encourage in others a critical attitude towards the many proliferating forms of ethical consumption. Altogether, this study provides insight into the ambiguity of ethical consumption enabling us to understand not only the tensions and practices but also the relationships and interconnections between different interpretations of ethical consumption. Bearing in mind that ethical consumption is by no means a new phenomenon (Gabriel and Lang, 1995); we suggest that the challenge for future studies might 
be to explore the trajectories of practices of ethical consumption from a historical perspective so that we can understand the ideological dynamics of the phenomenon more clearly.

\section{References}

Abu-Lughod, L. (1997) The interpretation of Culture(s) after television. Representations 59: 109134.

Anderson, T.W. Jr. and Cunningham, W.H. (1972) The Socially Conscious Consumer. Journal of Marketing 36: 23-31.

Attalla, A. and Carrigan, M. (2001) The myth of ethical consumer - do ethics matter in purchase behavior? Journal of Consumer Marketing 18(7): 560-577.

Barnett, C., Cloke, P., Clarke, N., and Malpass, A. (2005a) Consuming ethics: Articulating the Subjects and Spaces of Ethical consumption. Antipode 37(1): 23-45.

Barnett, C., Cafaro, P.and Newholm, T. (2005b) Philosophy and ethical consumption. In: Harrison, R., Newholm, T. and Shaw, D. (eds.) The Ethical Consumer. Wiltshire: SAGE, $11-24$.

Barnett, C., Cloke, P., Clarke, N., and Malpass, A. (2007) Globalising the Consumer: Doing politics in an ethical register. Political Geography 26: 231-249.

Beck, U. (1992) Risk society. Towards a new society. Wiltshire: SAGE Publications Ltd.

Beck, U. (1994) The Reinvention of Politics: Towards a Theory of Reflexive Modernization, In: Beck, U., Giddens, A. and Lash, S. (eds) Reflexive Modernization: Politics, Tradition and Aesthetics in the Modern Social Order. Cambridge: Polity: 1-55.

Berry, H. and McEachern, M. (2005) Informing ethical consumers. In: Harrison R, Newholm T. and Shaw D. (eds.) The Ethical Consumer. Wiltshire: SAGE Publications Ltd., 69-88.

Boltanski, L. and Thévenot, L. (1999) The sociology of critical capacity. European Journal of Social Theory 2(3): 359-377. 
Boltanski, L. and Thévenot, L. (2006) On Justification Economies of Worth. Princeton: Princeton University Press.

Carrigan, M., Szmigin, I. and Wright, J. (2004) Shopping for a better world? An interpretive study of the potential for ethical consumption within the older market. Journal of Consumer Marketing 21(6): 401-417.

Caruana, R. (2007) Morality and Consumption: towards a multidisciplinary perspective. Journal of Marketing Management 23(3-4): 207-225.

Cherrier, H. (2005) Using Existential-Phenomenological Interviewing to Explore meanings of Consumption. In: Harrison, R., Newholm, T. and Shaw, D. (eds.) The Ethical Consumer. Wiltshire: SAGE, 125-135.

Cherrier, H. (2007) Ethical consumption practices: Co-production of self-expression and social recognition. Journal of Consumer Behaviour 6: 321-335.

Clarke, N., Barnett, C., Cloke, P. and Malpass, A. (2006) Globalising the consumer: Doing politics in an ethical register. Political Geography 26: 231-249.

Connolly, J. and Prothero, A. (2003) Sustainable consumption: consumption, consumers, and the commodity discourse. Consumption, Markets and Culture 6(4): 275-291.

Connolly, J. and Prothero, A. (2008) Green Consumption: Life-politics, risk and contradictions. Journal of Consumer Culture 8: 117-145.

Devinney, M.T., Auger, P. and Eckhardt, G.M. (2010) The Myth of Ethical Consumer. Cambridge: Cambridge University Press.

Dolan, P. (2002) The Sustainability of "Sustainable Consumption” Journal of Macromarketing 22(2): 170-181.

Elgin, D. (1981) Voluntary Simplicity: Toward a Way of Life that is Outwardly Simple, Inwardly Rich. Morrow: New York. 
Etzioni, A. (1998) Voluntary simplicity: Characterization, select psychological implications, and societal consequences. Journal of Economic Psychology 19: 619-643.

Firat, F. and Venkatesh, A. (1995) Liberatory Postmodernism and the Reenchantment of Consumption. Journal of Consumer Research 22: 239-267.

Gabriel, Y. and Lang, T. (1995) The Unmanageable Consumer: Contemporary Consumption and its Fragmentations. London: SAGE Publications Ltd.

Geertz, C. (1973) The Interpretation of Cultures. New York: Basic Books.

Giddens, A. (1991) The Consequences of Modernity. Cambridge: Polity Press.

Goig, L. (2007) Fair trade and global cognitive orientation: a focus on Spanish fair trade consumers. International Journal of Consumer Studies 31: 468-477.

Halkier, B. (2001) Consuming Ambivalences: Consumer handling of environmentally related risks in food. Journal of Consumer Culture 1: 205-224.

Hall, S. (1997) The Work of Representation, In: Hall, S. (eds.) Representation: Cultural Representations and Signifying Processes, London: SAGE. pp. 13-74.

Harrison, R., Newholm, T. and Shaw, D. (2005) Defining the Ethical Consumer, In: Harrison R, Newholm T. and Shaw D. (eds.) The Ethical Consumer. Wiltshire: SAGE Publications Ltd., $1-8$.

Inglehardt, W. (2006) Modernization, Cultural Change and Democracy. New York: Cambridge University Press.

Kozinets, R.V. and Handelman, J.M. (1998) Ensouling consumption: a netnographic exploration of the meaning of boycotting behaviour. In Advances in Consumer Research, Joseph A., Wesley, H. (eds) Association for Consumer Research: Provo, UT (Vol. 25), 475-480.

Lehtonen, M. (2008) Individualismin aika [Age of Individualism]. In Häggman, K. (eds.) Suomalaisen arjen historia 4 [The history of Everyday Life In Finland 4], Helsinki : Weilin + Göös s. 165-175. pp. $273-285$.

Leire, C. and Tidell, A. (2005) Product-related environmental information to guide consumer 
purchases e a review and analysis of research on perceptions, understanding and use among Nordic consumers. Journal of Cleaner Production 13; 1061-1070.

Littler, J. (2005) Beyond the Boycott. Cultural Studies 19(2): 227-252.

MacIntyre, A. (1987) After Virtue: A study in moral theory. London: Duckworth.

McKee, H.A. and Porter J.E. (2009) The ethics of internet research A rhetorical, case-based process. New York: Peter Lang Publishing.

Micheletti, M. (2003) Political Virtue and Shopping: Individuals, Consumerism, and Collective action. New York: Palgrave Macmillan.

Moisander, J. and Valtonen, A. (2006) Qualitative Marketing Research: A Cultural Approach. Wiltshire: SAGE Publications Ltd..

Moisander, J. (2007) Motivational complexity of green consumerism. International Journal of Consumer Studies 31: 404-409.

Newholm, T. (2005) Case Studying Ethical Consumers Projects and Strategies, In: Harrison R, Newholm, T. and Shaw, D. (eds.) The Ethical Consumer. Wiltshire: SAGE Publications Ltd., 107-124.

Ozcaglar-Toulouse, N. (2007) Living for "Ethics": Responsible Consumption in Everyday Life. In: Belk, R.W. and Sherry, J.F. (eds) Research in Consumer Behavior Volume 11. Emerald Group Publishing Limited, 421-436.

Peterson, M.A. (2010) Imsukuhum, Kulhum! Modernity and Morality in Egyptian Children's Consumption. Journal of Consumer Culture 10(2): 233-253.

Prothero, A. McDonagh, P. and Dobscha, S. (2010) Is Green the New Black? Reflections on a Green Commodity Discourse. Journal of Macromarketing 30: 147-159.

Sassatelli, R. (2006) Virtue, Responsibility and Consumer Choice. Framing Critical Consumerism. In: Brewer, J. and Trentmann, F. (eds.) Consuming Cultures. Global Perspective. Berg: Oxford, 219-250. 
Schor, J.B., Slater, D., Zukin, S. and Zeliner, V.A. (2010) Critical and Moral Stances in Consumer Studies. Journal of Consumer Culture 10: 274-291.

Shamir, R. (2010) The age of responsibilization: on market-embedded morality. Economy and Society 37:1, 1-19.

Shankar, A, Cherrier, H. and Canniford R. (2006) Consumer enpowerment: a Foucauldian interpretation. European Journal of Marketing 10(9-10): 1013-1030.

Shaw, D., Shiu E. and Clarke, I. (2000) The contribution of ethical obligation and self-identity to the theory of planned behaviour: an exploration of ethical consumers. Journal of Marketing Management 16(8); 879-894.

Shaw, D. and Newholm, T. (2002) Voluntary simplicity and the ethics of consumption. Psychology and Marketing 19(2): 167-185.

Shaw, D. and Shiu E. (2003) Ethics in consumer choice: a Multivariate modelling approach. European Journal of marketing 37(10): 1485-1498.

Stillar, G.F. (1998) Analyzing Everyday Texts Discourse, Rhetoric, and Social Perspectives. Thousand Oaks: SAGE Publications Ltd.

Strong, C. (1997) The Problems of translating fair trade principles into consumer purchase behaviour. Marketing Intelligence and Planning 15(1): 32-37.

Szmigin, I. and Carrigan, M. (2006) Exploring the Dimensions of Ethical Consumption. European Advances in Consumer Research 7: 608-613.

Thompson, C.J. and Troester, M. (2002) Consumer value systems in the age of postmodern fragmentation: The case of the natural health microculture. Journal of Consumer Research 28: $550-57$.

Thorgersen, J. (2005) How may consumer policy empower consumers for sustainable lifestyles? Journal of Consumer Policy 28: 143-178.

Trentmann, F. (2007) Citizenship and Consumption. Journal of Consumer Culture 7(2): 147-158. 
Tulloch, J. and Lupton, D. (2002) Consuming risk, consuming science: The case of GM foods. Journal of Consumer Culture 2: 363-383.

Warde, A. (1997) Consumption, Food and Taste. London: SAGE Publications Ltd..

Warde, A. (2005) Consumption and Theories of Practice. Journal of Consumer Culture 5: 131-153. 